\title{
CCR5 Chemokine Receptor Mediates Recruitment of MHC Class II-Positive Langerhans Cells in the Mouse Corneal Epithelium
}

\section{Citation}

Yamagami, Satoru, Pedram Hamrah, Kazuhisa Miyamoto, Dai Miyazaki, Iva Dekaris, Tracey Dawson, Bao Lu, Craig Gerard, and M. Reza Dana. 2005. "CCR5 Chemokine Receptor Mediates Recruitment of MHC Class II-Positive Langerhans Cells in the Mouse Corneal Epithelium." Investigative Opthalmology \& Visual Science 46 (4) (April 1): 1201. doi:10.1167/iovs.04-0658.

\section{Published Version}

10.1167/iovs.04-0658

\section{Permanent link}

http://nrs.harvard.edu/urn-3:HUL.InstRepos:34428291

\section{Terms of Use}

This article was downloaded from Harvard University's DASH repository, and is made available under the terms and conditions applicable to Other Posted Material, as set forth at http:// nrs.harvard.edu/urn-3:HUL.InstRepos:dash.current.terms-of-use\#LAA

\section{Share Your Story}

The Harvard community has made this article openly available.

Please share how this access benefits you. Submit a story.

Accessibility 


\title{
CCR5 Chemokine Receptor Mediates Recruitment of MHC Class II-Positive Langerhans Cells in the Mouse Corneal Epithelium
}

\author{
Satoru Yamagami, ${ }^{1,2}$ Pedram Hamrah, ${ }^{1}$ Kazuhisa Miyamoto, ${ }^{1}$ Dai Miyazaki, ${ }^{1}$ \\ Iva Dekaris, ${ }^{1}$ Tracey Dawson, ${ }^{3}$ Bao Lu, ${ }^{4}$ Craig Gerard, ${ }^{4}$ and M. Reza Dana ${ }^{1}$
}

\begin{abstract}
Purpose. To characterize the chemokines and chemokine receptors that mediate the effect of proinflammatory cytokines, interleukin (IL)-1 and tumor necrosis factor (TNF)- $\alpha$, on the recruitment of MHC class $\mathrm{II}^{+}$Langerhans cells (LCs) in the corneal epithelium.

Methods. A standard model for corneal LC recruitment, application of cautery to the central corneal surface was used, and the differential gene expression levels of a panel of chemokines and chemokine receptors were determined by RNase protection assay. Chemokine receptor-knockout mice were used to evaluate the recruitment of MHC class $\mathrm{II}^{+}$LCs to the corneal epithelium. To determine the sensitivity of selected chemokines to IL-1 and TNF- $\alpha$ stimulation, the chemokine gene expression pattern was analyzed after blockade of IL-1 and TNF receptors.
\end{abstract}

RESULTS. CCR1, -2 , and -5 were overexpressed in corneas after cauterization. Topical administration of soluble TNF receptor I and IL-1 receptor antagonist, which abrogated corneal LC recruitment, significantly suppressed the gene transcription levels of the ligands of CCR 1 and/or -5 , regulated on activation normal T-cell expressed and secreted (RANTES), macrophage inflammatory protein (MIP)- $1 \alpha$, and MIP-1 $\beta$. The recruitment of major histocompatibility complex (MHC) class $\mathrm{II}^{+}$LC was significantly suppressed in $\mathrm{CCR} 5^{-/-}$mice and blockade of RANTES and MIP- $1 \beta$, but not in $\mathrm{CCR} 1^{-/-}, \mathrm{CCR} 2^{-/-}$MIP$1 \alpha^{-/-}$, or MIP- $1 \alpha^{-/-}$mice. The evaluation of epithelial $\mathrm{CD}_{11 \mathrm{c}^{+}}$LC cells by confocal microscopy revealed coexpression for $\mathrm{CCR} 5$ primarily among $\mathrm{B}^{-}\left(\mathrm{CD}^{-} 0^{-} / \mathrm{CD}^{-} 6^{-}\right)$subsets of these LCs but not among the mature $\mathrm{B}^{+}$subsets of $\mathrm{CD} 11 \mathrm{c}^{+} \mathrm{LCs}$. Concuusions. These data suggest that CCR5 plays a critical role in mediating recruitment and mobilization of $\mathrm{MHC}$ class $\mathrm{II}^{+}$

From ${ }^{1}$ The Laboratory of Immunology, Schepens Eye Research Institute, Harvard Medical School, Boston, Massachusetts; the ${ }^{2}$ Department of Corneal Tissue Regeneration, University of Tokyo Graduate School of Medicine, Tokyo, Japan; the ${ }^{3}$ Department of Pathology, University of North Carolina, Chapel Hill, North Carolina; and ${ }^{4}$ The Perlmutter Laboratory, Children's Hospital, Harvard Medical School, Boston, Massachusetts

Supported National Eye Institute Grant EY12963 (MRD); the Eye Bank Association of America (MRD); Fellowships from Bausch \& Lomb (SY, DM), Scientific Research from the Ministry of Education (SY), the Japan National Society for the Prevention of Blindness (SY); and Balokovic Scholarship from Harvard University (ID).

Submitted for publication June 6, 2004; revised October 24, 2004; accepted November 11, 2004

Disclosure: S. Yamagami, None; P. Hamrah, None; K. Miyamoto, None; D. Miyazaki, None; I. Dekaris, None; T. Dawson, None; B. Lu, None; C. Gerard, None; M.R. Dana, Amgen Corp. (F)

The publication costs of this article were defrayed in part by page charge payment. This article must therefore be marked "advertisement" in accordance with 18 U.S.C. $\$ 1734$ solely to indicate this fact.

Corresponding author: Satoru Yamagami, Department of Corneal Tissue Regeneration, Tokyo University Graduate School of Medicine, Bunkyo-ku, Tokyo, 113-8655, Japan; syamagami-tky@umin.ac.jp.
LCs into the corneal epithelium. Targeting CCR5 and its ligands may be a new strategy for modulating immunity. (Invest Ophthalmol Vis Sci. 2005;46:1201-1207) DOI:10.1167/iovs.040658

T angerhans cells (LCs) are a specialized subpopulation of bone marrow-derived dendritic cells (DCs), which, in addition to their well-characterized function in the skin, are part of the professional antigen-presenting cell (APC) population of the ocular surface. ${ }^{1}$ Recent data from our laboratory have revealed that the epithelium of the normal mouse cornea contains both resident $\mathrm{CD} 11 \mathrm{c}^{+}$major histocompatibility complex (MHC) class II-negative LCs as well as CD11 ${ }^{+}$MHC class II-positive LCs. $^{2}$ These MHC class $\mathrm{II}^{-}$LCs exist, not only in the corneal periphery and limbus, but also exclusively in the central and paracentral corneal epithelium, ${ }^{2}$ where $\mathrm{MHC}$ class $\mathrm{II}^{+}$ LCs are totally absent. ${ }^{2-4}$ Although the immunologic role of MHC class II $^{-}$LCs remains unknown, the critical role of MHC class $\mathrm{II}^{+}$LCs in initiating immunogenic and specifically T-cellmediated inflammation in the cornea and ocular surface is well established. ${ }^{3,5,6}$

In the corneal epithelium, several inflammatory stimuli and corneal diseases (e.g., alkali or thermal burns and infection) have been shown to induce recruitment of MHC class $\mathrm{II}^{+} \mathrm{LCs}$ into the central cornea, where they may initiate Ag processing. ${ }^{7-10}$ For example, in herpetic keratitis, migration of MHC class $\mathrm{II}^{+}$LCs into the cornea is associated with significant exacerbation of disease. ${ }^{7,11}$ Further, the existence of MHC class $\mathrm{II}^{+}$LCs in the center of the cornea is critical in the innate immune response to Pseudomonas aeruginosa. ${ }^{12}$ Moreover, the microanatomic distribution of $\mathrm{MHC}$ class $\mathrm{II}^{+}$ocular surface LCs, specifically the fact that MHC class $\mathrm{II}^{+}$cells are absent from the central cornea, has been related to the immune privilege of the cornea and the generally favorable prognosis of corneal allografts. ${ }^{13-15}$ Conversely, the poor prognosis of "high-risk" corneal allografts, where the donor tissue is engrafted onto inflamed and vascularized host beds, has been associated with the significant endowment of MHC class $\mathrm{II}^{+}$ corneal LCs in the transplant bed, which can facilitate allosensitization. ${ }^{14,16}$ These findings suggest that the mobilization and distribution of MHC class $\mathrm{II}^{+}$LCs in the central areas of the cornea can alter the clinical course of a variety of corneal diseases.

Despite the critical role of LCs as "professional" APCs, the molecular mechanisms that mediate their recruitment into ocular tissues are only partially understood. IL-1 has been reported to play a critical role in the recruitment of MHC class $\mathrm{II}^{+}$LCs in not only the cornea, ${ }^{17,18}$ but also the skin. ${ }^{19}$ Conversely, topical administration of an IL-1 receptor antagonist (IL-1ra), a natural and potent antagonist of IL-1RI, has been shown to suppress significantly the recruitment of MHC class $\mathrm{II}^{+}$LCs into the central cornea. ${ }^{5}$ In addition to IL- 1 , TNF- $\alpha$ has been implicated in the migration of skin LCs. ${ }^{20,21}$ Similarly, we have shown that TNF- $\alpha$ (through the activity of its receptors p55 [TNFR-I] and p75 [TNFR-II]) is a critical mediator of MHC 
TABLE 1. Primary and Respective Control Antibodies

\begin{tabular}{lll}
\hline Primary Ab (Clone) & \multicolumn{1}{c}{ Specificity } & Control Ab \\
\hline Ia ${ }^{\mathrm{d}}$-FITC (39-10-8) & BALB/c mouse class II MHC Ag & Mouse IgG-FITC \\
Ia ${ }^{\mathrm{b}}$-FITC (AF6-120.1) & C57BL/6 or C57BL.129 mouse class II MHC Ag & Mouse IgG-FITC \\
CD11c (HL3) & Integrin DC/LC marker & Hamster IgG \\
CD45 (30-F11) & Panleukocyte marker & Rat IgG2b \\
CD80-FITC (16-10AI) & B7.1 costimulatory molecule & Hamster IgG \\
CD86-PE (GL1) & B7.2 costimulatory molecule & Rat IgG2a \\
CCR1 (C-20) & CC chemokine receptor 1 & Goat IgG \\
CCR5 (M-20) & CC chemokine receptor 5 & Goat IgG \\
RANTES $(53405)$ & RANTES/CCL5 & Rat IgG2a \\
MIP-1 $\beta(46907)$ & MIP-1 $\beta /$ CCL4 & Rat IgG2a \\
\hline
\end{tabular}

class $\mathrm{II}^{+} \mathrm{LC}$ recruitment into the cornea and that it can partially mediate the activity of IL-1 in recruiting corneal LCs. ${ }^{4}$ However, although animals with gene-targeted deficiency of both p55 and p75 exhibited impaired corneal LC recruitment, we could not uniformly detect TNFR expression by all corneal LCs that migrated into the cornea in response to inflammation. Therefore, we have hypothesized, ${ }^{4}$ but thus far have not provided proof, that the effect of proinflammatory cytokines on the recruitment of $\mathrm{MHC}$ class $\mathrm{II}^{+}$LCs is not direct, but rather is mediated through select inducible chemokines that are generated in response to local inflammation. Herein, we provide data, using an established experimental model of inflammatory keratitis associated with the expression of MHC class $\mathrm{II}^{+} \mathrm{LCs}$, that differential overexpression of select chemokines and chemokine receptors, notably CCR5 and its ligands, mediates the IL-1 and TNF- $\alpha$-induced recruitment of ocular surface MHC class $\mathrm{II}^{+}$LCs in the central corneal epithelium.

\section{Materials ANd Methods}

\section{Animals}

Unless otherwise noted, BALB/c $\left(\mathrm{H}-2^{\mathrm{d}}\right)$ mice (Taconic Farm, Germantown, NY) were used for chemokine and chemokine receptor mRNA detection studies. Gene knockout (KO) strains tested, included mice with homozygous deficiency of CCR5 (CCR $5^{-1-}$, C57BL/129 background from Jackson Laboratory, Bar Harbor, ME), CCR2 ${ }^{-1-}$ MIP- $1 \alpha^{-1-}$ (C57BL/129 background), MIP-1 $\alpha^{-/-}$(C57BL/6; Jackson Laboratory), and CCR1 (CCR1 ${ }^{-1-}, \mathrm{C} 57 \mathrm{BL} / 129$ background). ${ }^{22}$ The wild-type control animals (C57BL/129 and C57BL/6) were procured originally from Jackson Laboratory and were subsequently bred at the Schepens Eye Research Institute animal colony. All experiments used male mice that were 6 to 12 weeks of age. All animals were treated in accordance with the ARVO Statement for the Use of Animals in Ophthalmic and Vision Research.

\section{Antibodies}

The primary antibodies (Abs), their specificity, and their respective control Abs are summarized in Table 1. CCR1 and CCR5 Abs were purchased from Santa Cruz Biotechnology (Santa Cruz, CA). Regulated on activation, normal T-cell expressed and secreted (RANTES)/CCL5, macrophage inflammatory protein (MIP)- $1 \beta / \mathrm{CCL} 4 \mathrm{Abs}$, and their isotype control (rat IgG2a) were obtained from R\&D Systems (Minneapolis, MN). The other primary Abs were from BD PharMingen (San Diego, CA). The secondary antibodies were Cy5-conjugated goat antiArmenian hamster IgG (BD PharMingen), and FITC- and rhodamineconjugated donkey anti-goat IgG and rhodamine-conjugated goat antirat IgG (Santa Cruz Biotechnology).

\section{Induction of MHC Class $\mathrm{II}^{+}$LC Recruitment and Enumeration}

Mice were deeply anesthetized with an intraperitoneal injection of 3 to $4 \mathrm{mg}$ ketamine and $0.1 \mathrm{mg}$ xylazine and placed under the operating microscope. Unless noted otherwise, ocular major histocompatibility complex (MHC) class $\mathrm{II}^{+} \mathrm{LC}$ recruitment into the central and paracentral cornea was induced by application of thermal cautery. With the tip of a hand-held cautery (Aaron Medical Industries Inc., St. Petersburg, FL), seven to nine burns were applied to the surface of the central area of the cornea to induce MHC class $\mathrm{II}^{+} \mathrm{LC}_{\text {recruitment into the corneal }}$ epithelium, as previously described. ${ }^{4}$ Antibiotic ophthalmic ointment was applied immediately after all eye surgeries. At select time points after corneal cauterization ( $n=6-10$ mice per time point), corneas were harvested, and LC enumeration was performed in whole corneal epithelial sheets by use of indirect immunofluorescence, as described elsewhere..$^{4,5}$ Briefly, corneas were removed and placed in $20 \mathrm{mM}$ EDTA buffer for 30 minutes at $37^{\circ} \mathrm{C}$. The epithelium was detached and washed in phosphate-buffered saline (PBS) at room temperature. After fixation with $95 \%$ alcohol, epithelial sheets were incubated with primary anti-mouse $\mathrm{Ia}^{\mathrm{d}} \mathrm{Ab}$ for BALB/c mice, or with anti-mouse $\mathrm{Ia}^{\mathrm{b}} \mathrm{Ab}$ for $\mathrm{C} 57 \mathrm{BL} / 6$ or $\mathrm{C} 57 \mathrm{BL} / 129$ mice for 30 minutes at $37^{\circ} \mathrm{C}$ to detect respective strain-specific MHC class $\mathrm{II}^{+}$LCs. Isotype-matched control antibodies and secondary antibodies alone were used as negative controls. Epithelial sheets were washed twice in PBS and incubated with FITCconjugated goat anti-mouse secondary $\mathrm{Ab}$ for 30 minutes at $37^{\circ} \mathrm{C}$. Samples were mounted on slides and examined under the fluorescence microscope. MHC class $\mathrm{II}^{+}$LCs in the central and paracentral (central $2 \mathrm{~mm}$ ) of the cornea were enumerated using a square ocular grid and quantified as LCs per square millimeter.

\section{RNA Preparation and RNase Protection Assay}

At select time points after corneal surgery ( $n=6-10$ corneas per time point per experiment), total RNA was extracted by the single-step method (RNA-STAT-60; Tel-Test Inc., Friendswood, TX). Briefly, whole corneas were homogenized and centrifuged to remove cellular debris. The RNA pellet was resuspended in nuclease-free water and processed together as a group. Detection and quantification of murine chemokine mRNAs were performed with a multiprobe RPA system (BD Bioscience, Franklin Lake, NJ), as recommended by the supplier and as we have previously described. ${ }^{23}$ Briefly, a mixture of $\left[\alpha^{-32} \mathrm{P}\right]$ UTP-labeled antisense riboprobe was generated from the chemokine template set mCK-5 and mCR-5 (BD Bioscience). Ten micrograms of total RNA was used in each sample. Total RNA was hybridized overnight at $56^{\circ} \mathrm{C}$ with $300 \mathrm{pg}$ of the ${ }^{32} \mathrm{P}$-anti-sense riboprobe mixture. After purification by ethanol precipitation, the samples were resolved on $5 \%$ polyacrylamide sequencing gels. The gels were dried and subjected to autoradiography. Protected bands were observed after exposure of gels to $\mathrm{x}$-ray film. The bands were quantitated by densitometric analysis and were normalized to averaged density of L32 and GAPDH.

\section{Suppression of MHC Class $\mathrm{II}^{+}$LC Recruitment with Topical IL-1Ra and Soluble TNFR-I Administration}

To determine alterations in chemokine and chemokine receptor expression as a result of local immunotherapies that suppress ocular LC migration, we topically applied IL-1 ra $(2 \mathrm{mg} / \mathrm{mL}$; kindly provided by 


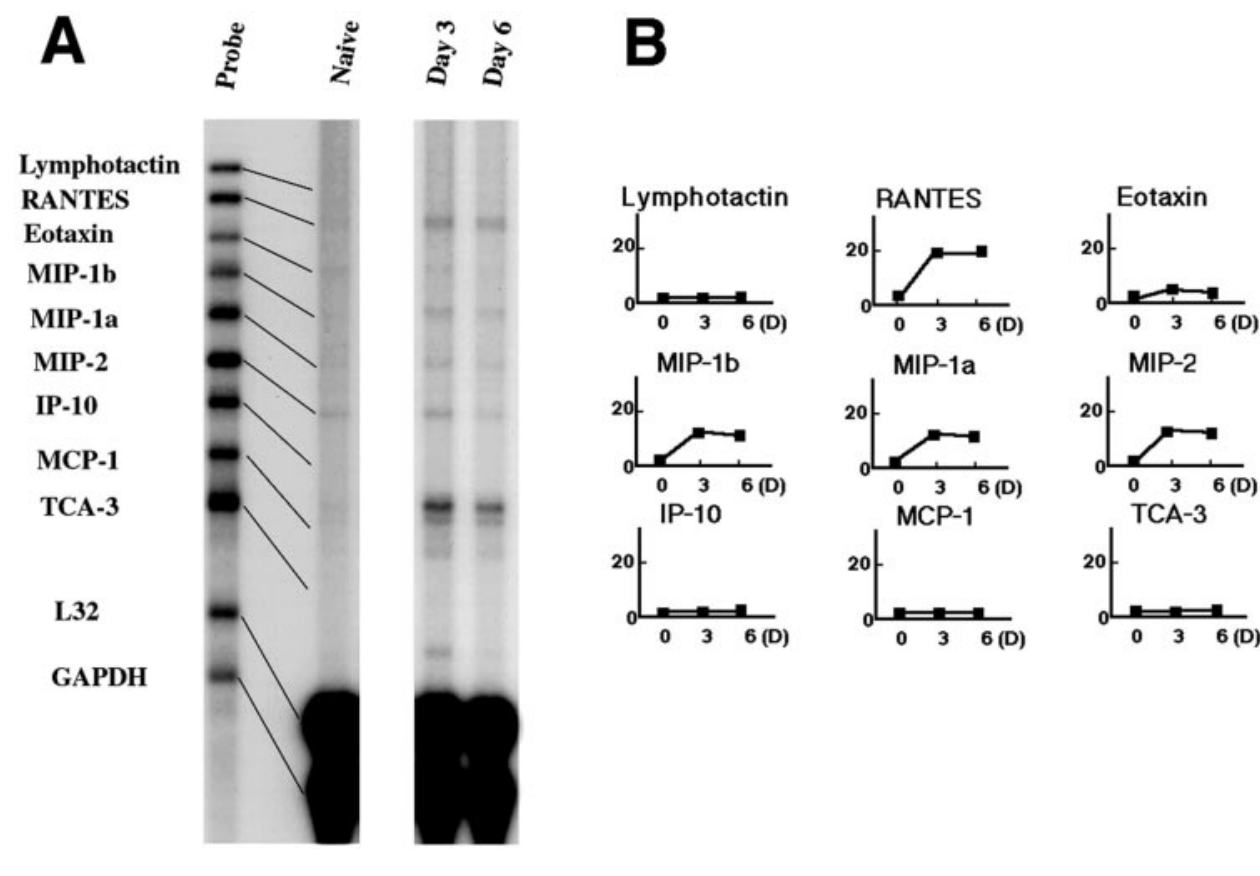

Figure 1. Chemokine gene expression in the cornea after cautery. (A) Autoradiography data. On the basis of the migration pattern of the undigested probes, specific bands were identified for each chemokine. (B) Densitometric analyses normalized to L32 and GAPDH. Vertical axes indicate arbitrary units based on densitometry. There was overexpression of RANTES, MIP- $1 \alpha$, MIP- $1 \beta$, and MIP-2 mRNA in corneas on days 3 and 6 after cauterization. Minimal levels of eotaxin were detectable on day 3 after cautery. Two sets of results on separate experiments were analyzed, and averaged density is shown as the results of densitometric analysis.
Ulrich Feige; Amgen Corp., Thousand Oaks, CA) and soluble (s) TNFR-I ( $15 \mathrm{mg} / \mathrm{mL}$; kindly provided by Carl Edwards, Amgen Corp.) eye drops four times daily after cauterization until tissues were harvested. Eye drops containing the vehicle $(0.2 \%$ hyaluronic acid) were used in the same manner as in the control mice. On days 3 and 6 after cauterization, corneas ( $n=10$ per time point per experiment) were removed in both groups and homogenized (RNA-STAT-60; Tel-Test) and stored at $-70^{\circ} \mathrm{C}$ for RNA extraction and RPA analysis. All experiments were repeated at least twice; representative data are presented.

\section{Effect of MHC Class II $^{+}$LC Recruitment with Subconjunctival Injection of Anti-RANTES and MIP-1及 Abs}

After cautery, subconjunctival injection was performed with a $100-\mu \mathrm{L}$ glass syringe (Hamilton Co., Reno, NV) with a 30-gauge needle. A total of $5 \mu \mathrm{L}(5 \mu \mathrm{g} \mathrm{each})$ of rat anti-mouse RANTES and anti-mouse MIP-1 $\beta$ neutralized Abs was injected on the day of the cautery and 2 and 4 days after surgery. The same amount of rat IgG2a was used as a control. MHC class $\mathrm{II}^{+}$LCs in the central and paracentral of the cornea were enumerated on day 6 .

\section{Evaluation for $\mathrm{CCR1}^{+}$and $\mathrm{CCR} 5^{+}$Cells in Corneal Epithelial Sheets}

Mice were killed on days 3 and 6 after cauterization, and corneas were excised from BALB/c mice. Corneal epithelium sheets were removed as described earlier and fixed in acetone for 15 minutes at room temperature (RT). To block nonspecific staining, epithelial sheets were incubated in $2 \%$ bovine serum albumin (BSA) diluted in PBS (PBS-BSA) for 15 minutes before addition of primary and secondary antibodies. Purified primary antibodies or isotype-matched control antibodies were applied to the samples for 2 hours, followed by a 60 -minute incubation of a second FITC- or PE-conjugated primary antibody or by incubation of the secondary antibodies for 60 minutes (all diluted for optimal concentrations in PBS-BSA). Epithelial sheets were further stained with secondary antibodies only, as additional controls. All staining procedures were performed at RT, and each step was followed by three thorough washings in PBS for 5 minutes each. Finally, epithelial sheets were covered with mounting medium (Vector, Burlingame, CA) and examined with a confocal microscope (Leica TCS 4D; Lasertechnik, Heidelberg, Germany). Epithelial sheets were examined at 160- and 400-fold magnifications using a $\times 10$ eyepiece and $\times 16$ or $\times 40$ objective lens. At least three different corneas were examined per each double-staining experiment. In addition to detection of MHC class $\mathrm{II}^{+}$cells, corneal LCs were identified by use of anti-mouse CD11c Ab and anti-mouse $\mathrm{CD} 45 \mathrm{Ab}$.

\section{Statistical Analysis}

The Mann-Whitney test was used to compare the number of LCs in the corneal epithelium under different experimental conditions. All experiments were repeated at least twice unless noted. $P<0.05$ was considered significant.

\section{Results}

\section{Differential Chemokine Gene Expressions Associated with Corneal LC Recruitment and Mobilization}

Experimental induction of MHC class $\mathrm{II}^{+}$corneal LC migration was followed by RPA analysis to determine the upregulation of involved chemokine and chemokine receptor genes in this model. The results of MHC class $\mathrm{II}^{+} \mathrm{LC}$ enumeration in the central and paracentral areas of the corneal epithelium on day 6 after cauterization showed a profound increase in the number of LCs (data not shown). Figure 1 shows the results of the chemokine RPA autoradiography, demonstrating the mRNA quantities of chemokines normalized to averaged density of L32 (a ribosomal protein) and GAPDH. The chemokines RANTES, MIP- $1 \alpha$, MIP-1 $\beta$, and MIP-2 genes were overexpressed in cauterized corneas on both days 3 and 6 after cautery, compared with expression in normal uninflamed corneas. Further, minimal levels of eotaxin were detectable on day 3 after cautery. Moreover, there was no gene expression for lymphotactin, interferon- $\gamma$ inducible protein (IP)-10, monocyte chemoattractant protein (MCP)-1, and T-cell activation gene (TCA)-3 in corneas at any of the time points studied. The striking overexpression of CC $(\beta)$ chemokine ligand genes, led us to analyze further the differential gene expression of the CC chemokine receptors. Overexpression was observed for the chemokine receptors CCR1, -2 , and -5 (Fig. 2). In contrast, CCR1b, -3, and -4 were not expressed in normal or cauterized corneas at any time point. 


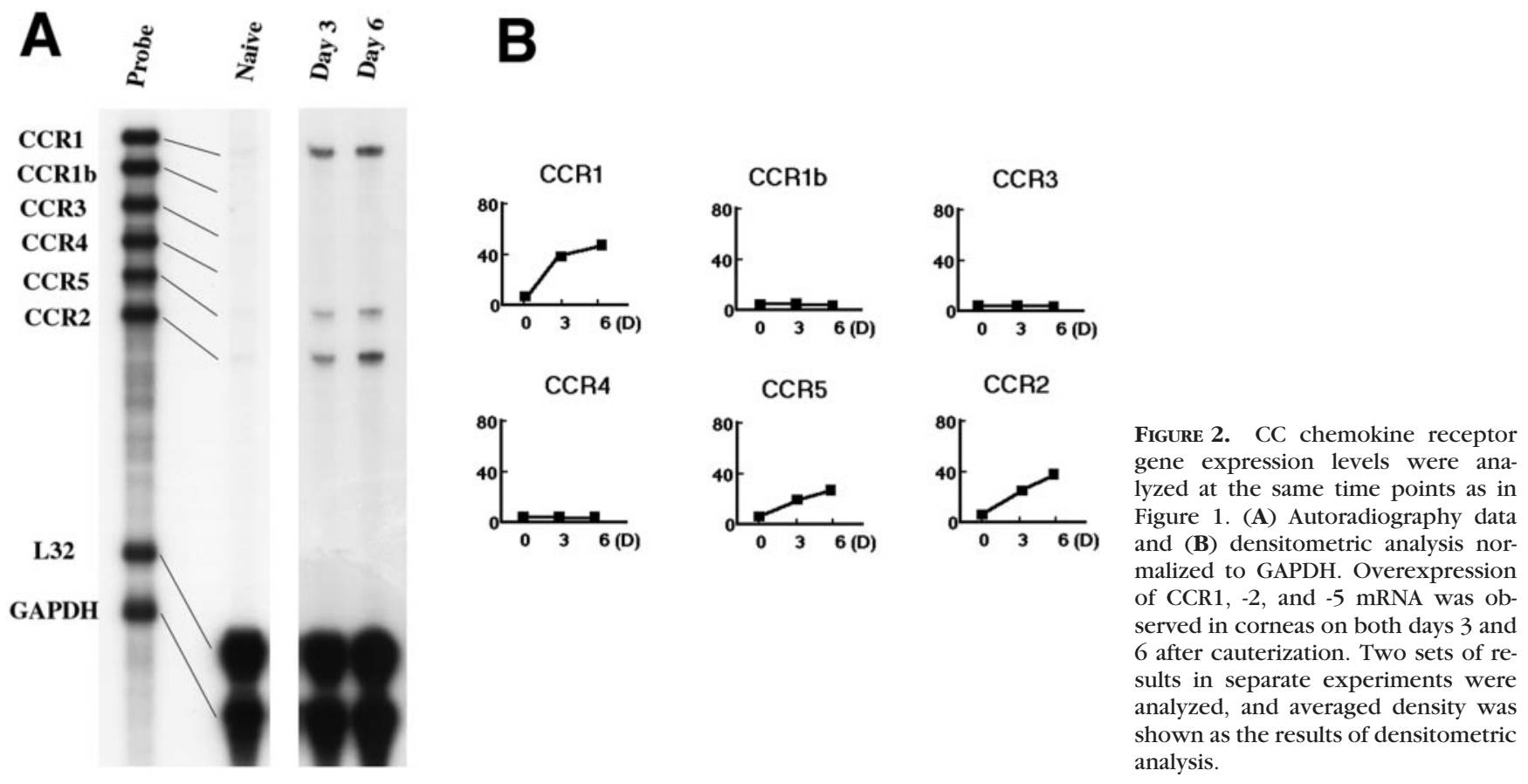

\section{Suppression of LC Migration by IL-1R Antagonist and Soluble TNF Receptor (R) I}

We have shown that the blockade of IL-1 or TNF- $\alpha$ function (through receptor blockade or gene knockout strategies) can suppress the recruitment of MHC class $\mathrm{II}^{+}$LCs to the central corneal epithelium. ${ }^{4,5,16,24}$ In this set of experiments we applied topical sTNFR-I and/or IL-1ra to corneas, to suppress the local IL- $1^{24}$ and TNF- $\alpha^{25}$ activity. The application of sTNFR-I alone to cauterized corneas led to a $40 \%$ and $47 \%$ reduction in the number of MHC class $\mathrm{II}^{+}$LCs in the central cornea, by 1 and 2 weeks after cautery, respectively, compared with vehicle controls $(P<0.01$; data not shown). However, the simultaneous blockade of both TNF- $\alpha$ and IL-1 through the combined application of IL-1 ra and sTNFR-I led to an undetectable number of MHC class $\mathrm{II}^{+}$LCs in the corneas, suggesting the abrogation of LC migration into the cornea $(P<0.001$; data not shown). To evaluate further the effect of the topical immunomodulatory strategies used in the study on chemokine expression, treated corneas were harvested, and chemokine gene expression assayed on days 3 and 6 after administration of IL-1 ra and sTNFR-I (or control vehicle) subsequent to tissue cauterization. Figure 3 shows the results of the chemokine RPA autoradiography and their densitometric analyses normalized to averaged density of L32 and GAPDH. RANTES; eotaxin; and MIP- $1 \alpha,-1 \beta$, and -2 mRNAs were all expressed abundantly on day 3 in both the treated and the placebo groups. However, whereas the genes of RANTES, MIP- $1 \alpha$, and MIP- $1 \beta$ were still expressed at day 6 in the placebo group, corneas treated with IL-1 ra and sTNFR-I demonstrated no or minimal levels of gene expression for these chemokines. Treatment with IL-1ra and sTNFR-I however, did not affect the expression levels of eotaxin and MIP-2 genes at day 6.

\section{Recruitment of MHC Class $\mathrm{II}^{+}$Corneal LCs in CCR5- and CCR1-KO Mice}

To differentiate further which CCR system is more closely associated with the recruitment of $\mathrm{MHC}$ class $\mathrm{II}^{+} \mathrm{LCs}, \mathrm{KO}$ mice lacking the genes for CCR1 (CCR $\left.1^{-/}\right)$, CCR2/MIP-1 $\alpha$ $\left(\mathrm{CCR}^{-{ }^{-}-}\right.$MIP- $\left.1 \alpha^{-/-}\right), \quad \mathrm{MIP}-1 \alpha \quad\left(\mathrm{MIP}-1 \alpha^{-/-}\right)$, or CCR5 $\left(\mathrm{CCR} 5^{-/-}\right)$were used to analyze the ability of ocular surface
LCs to migrate into the cornea, by enumeration of MHC class $\mathrm{II}^{+}$LCs in the epithelium after cautery. No significant differences in the number of MHC class $\mathrm{II}^{+}$LCs was observed between CCR1-KO, CCR2/MIP- $1 \alpha$ double-KO, MIP- $1 \alpha$-KO, and respective wild-type control animals (Fig. 4A-C) after cautery. In contrast, the number of MHC class $\mathrm{II}^{+}$LCs in the central cornea, was significantly reduced $(>50 \%)$ in CCR5-KO mice compared with wild-type control mice $(P<0.005)$ on day 6 after cautery (Fig. 4D).

\section{Effect of MHC Class $\mathrm{II}^{+}$LC Recruitment with Subconjunctival Injection of Anti-RANTES and MIP-1 $\beta$ Abs}

Although RANTES, MIP- $1 \alpha$, and MIP- $1 \beta$ are the ligands of CCR 5 and are upregulated after cautery, MIP- $1 \alpha-\mathrm{KO}$ mice did not show MHC class $\mathrm{II}^{+}$LCs migration (Fig. 4C). Therefore, blocking experiments were performed with subconjunctival injection of RANTES and MIP-1 $\beta$ neutralizing Abs. As shown in Figure 5 , the number of MHC class $\mathrm{II}^{+}$LCs significantly decreased in corneal epithelia of anti-RANTES/MIP-1 $\beta$ Abs treatment group compared with those of the isotype control group.

\section{Expression of CD80, CD86, and MHC Class II Antigens in $\mathrm{CCR}^{+}$Corneal LCs}

The data herein suggest that CCR5 activity is functionally associated with an increase in MHC class $\mathrm{II}^{+}$LCs and their migration into inflamed corneas. To determine whether this effect was mediated directly through CCR5 (i.e., at the level of epithelial LCs) or indirectly (i.e., through a CCR5-dependent recruitment of another leukocyte population that could in turn lead to LC migration), we performed immunohistochemistry on normal and inflamed corneas to evaluate the expression of CCR5 and -1. In the normal uninflamed cornea, CD $45^{+} \mathrm{CD} 11 \mathrm{c}^{+}$ DCs were uniformly $\mathrm{B}^{-}\left(\mathrm{CD}^{-} 0^{-} / \mathrm{CD}^{-} 6^{-}\right)$, both in the central epithelium and stroma, indicating their immature phenotype, as recently described. ${ }^{2,26,27}$ In addition, analysis of normal corneas revealed all epithelial LCs to be uniformly CCR5 ${ }^{-}$and $-1^{-}$, regardless of location. However, by day 6 after cautery, CCR $5^{+}$corneal LCs were observed in significant numbers in the limbal and to a lesser degree in the peripheral corneal 


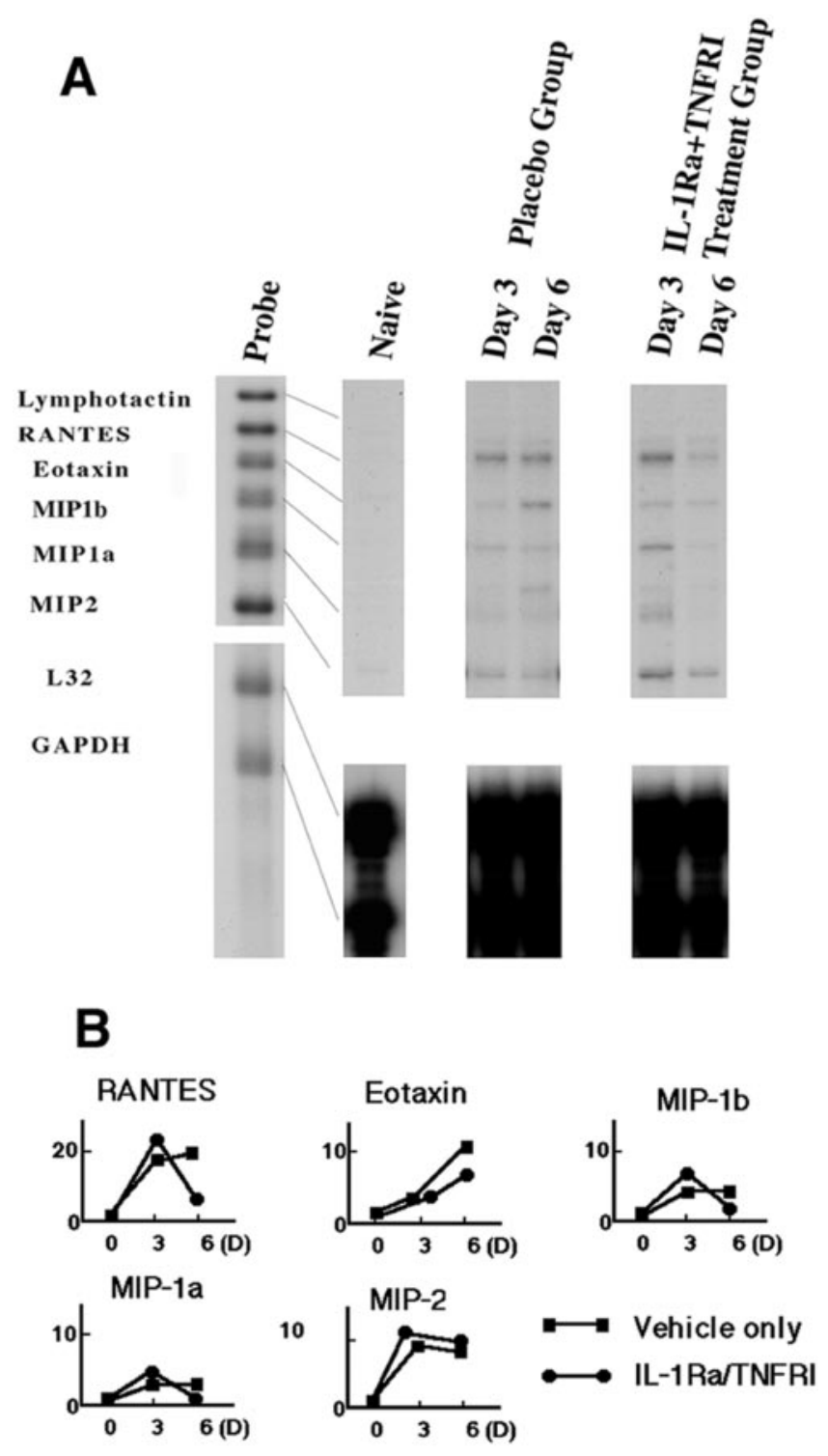

FigURE 3. Chemokine gene expression in corneas was analyzed on days 3 and 6 after cautery under the topical administration of simultaneous IL-1ra and TNFRI eye drops after cauterization. (A) Chemokine RPA autoradiography and (B) densitometric analyses normalized to GAPDH. RANTES, eotaxin, MIP-1 $\alpha$, MIP- $1 \beta$, and MIP-2 mRNA were expressed on day 3 in both the IL-1ra- and TNFRI-treated and the placebo groups. Although RANTES, MIP- $1 \alpha$, and MIP- $1 \beta$ gene expression levels were maintained on day 6 in the placebo group, chemokine gene expressions were suppressed in the IL-1 ra- and TNFRI-treated group. In addition, treatment with IL-1ra and TNFRI did not affect the expression levels of eotaxin and MIP-2 genes. Two sets of results on separate experiments were analyzed, and averaged density was shown as the results of densitometric analysis.

epithelium (Figs. 6A-C). MHC class $\mathrm{II}^{+}$LCs, present in large numbers in the limbal and peripheral epithelium, were mostly $\mathrm{CCR}^{-}$on both days 3 (Figs. 6D, 6E) and 6 after cautery. In inflamed corneas, LCs expressing CD80 (Fig. 6F) and CD86 (data not shown) were observed immediately adjacent to the maximally inflamed areas around cautery sites. These $\mathrm{B} 7^{+} \mathrm{LCs}$, however, most of which also expressed MHC class II, failed to express CCR5, suggesting that the acquisition of maturation markers (Ia and costimulatory factors) is associated with the downregulation of CCR5 gene expression. Finally, epithelial LCs in inflamed corneas were uniformly CCR $1^{-}$at any of the
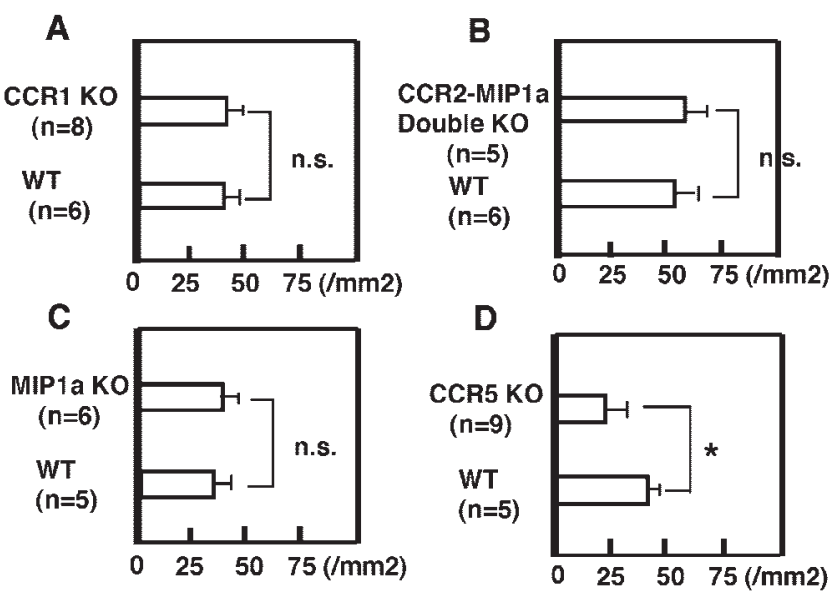

Figure 4. Enumeration of MHC class $\mathrm{II}^{+}$LCs in CCR1-, CCR2/MIP-1 $\alpha$ double-, MIP-1 $\alpha$-, and CCR5-KO mice. (A) No significant difference in the number of MHC class $\mathrm{II}^{+}$LCs was observed between the CCR1-KO mice and the wild-type controls. (B) CCR5-KO mice, however, show a significant reduction in MHC class $\mathrm{II}^{+}$LCs compared with the wildtype control mice. Two sets of results in separate experiments were analyzed, and representative data are shown. ${ }^{*} P=0.0074$.

time points studied, although CCR $1^{+}$DCs were detected in the corneal stroma after cauterization (data not shown).

\section{Discussion}

Chemokines have been subdivided into different families based on the relative position of their cysteine residues. ${ }^{28}$ In the CC $(\beta)$ chemokine group, which is primarily involved in recruitment of immune cells such as APCs and T cells, ${ }^{28,29}$ the first two cysteine residues are adjacent to each other. RANTES, eotaxin, MIP- $1 \alpha$, MIP-1 $\beta$, MCP-1, and TCA3 are part of the CC chemokine family. The CXC $(\alpha)$ chemokine family, in contrast, which includes IP-10, IL-8, and MIP-2, has the first two cys-

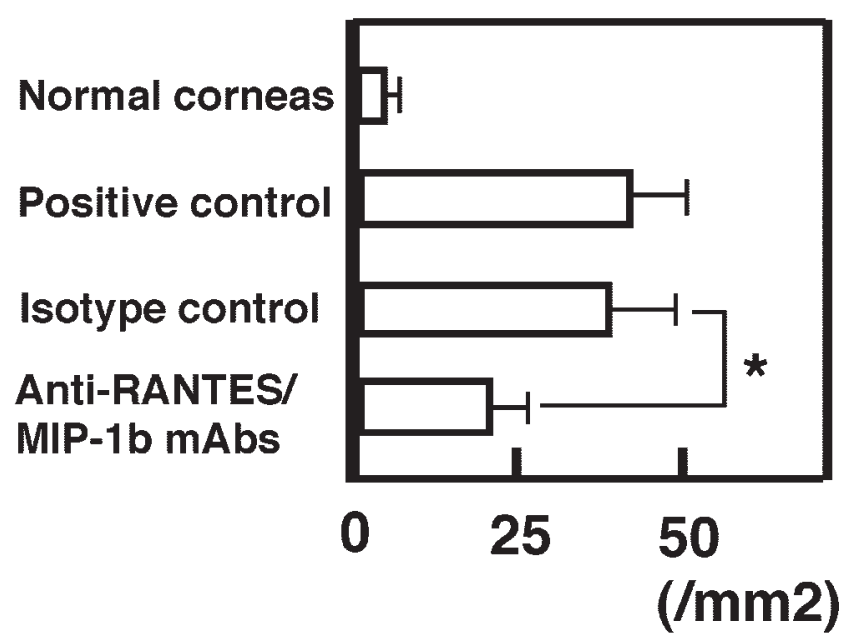

Figure 5. Enumeration of MHC class $\mathrm{II}^{+}$LCs on day 6 after cauterization in the corneal epithelium treated with subconjunctival injection of anti-RANTES/MIP-1 $\beta$ Abs. Subconjunctival injections were performed on days 0,2 , and 4 . The number of MHC class $\mathrm{II}^{+} \mathrm{LCs}$ decreased significantly in the epithelium of anti-RANTES/MIP-1 $\beta$ Abstreated corneas, compared with isotype control IgG2a-treated corneas. Positive control indicates no subconjunctival injection group after cautery. Two sets of results on separate experiments were analyzed, and representative data are shown. ${ }^{*} P=0.0078$. 

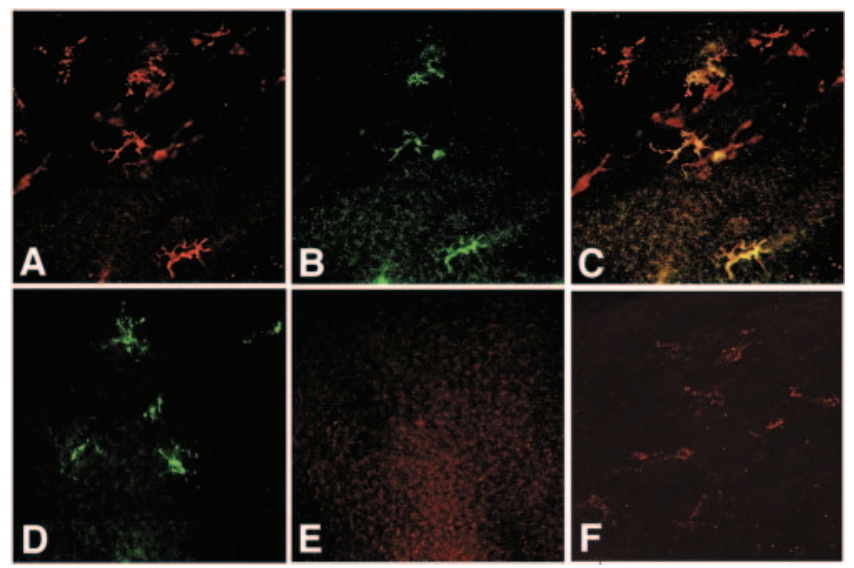

FigURE 6. Immunohistochemical studies by confocal microscopy (A-C) On day 6 after cautery, CD $45^{+}$dendritiform LCs (red) expressed CCR5 (green) in the corneal epithelium. (A) $\mathrm{CD} 45^{+}$(red), (B) CCR5 ${ }^{+}$ (green), (C) merger of (A) and (B), costained (yellow). (D) MHC class $\mathrm{II}^{+}$LCs (green) as shown in (D) did not express CCR5 (red; E). On day 6 after cautery, LCs expressing CD80 (red; F) did not express CCR5 (green) in the corneal epithelium.

teines separated by one amino acid residue. Chemokines form a complex functional network in a variety of inflammatory, infectious, and immune-mediated diseases, both locally and systematically. Whereas CXC chemokines (e.g., MIP-2 and Gro- $\alpha$ ) have been shown to mediate the recruitment of neutrophils $^{30}$ and CC chemokines, and their receptors have been demonstrated to be critical in regulating the recruitment of DCs, including LCs. ${ }^{31-37}$

In the present study, thermal cautery, which led to an increase in MHC class $\mathrm{II}^{+}$LCs in the central areas of the corneal epithelium, was associated with an overexpression of the chemokines RANTES, MIP- $1 \alpha$, MIP-1 $\beta$, eotaxin, and MIP-2, but not IP-10, MCP-1, and lymphotactin. In addition, CCR1 (e.g., RANTES, MIP-1 $\alpha$, MCP-3), CCR2 (MCP-1, -2, and -3), and CCR5 (e.g., RANTES, MIP-1 $\alpha$, MIP-1 $\beta)^{38,39}$ receptor genes, but not CCR3 (eotaxin) or -4 (MDC) receptor genes are overexpressed at the same time points after cautery. Because the initial data primarily implicated the CCR1, -2 , and -5 to be associated with the increase of MHC class $\mathrm{II}^{+}$LCs in the central cornea, we further assessed the functional relevance of these CC receptors by studying the recruitment of MHC class $\mathrm{II}^{+}$LCs in CCR1-, CCR2/MIP-1 $\alpha$-, MIP-1 $\alpha$-, and CCR5-KO mice compared with respective wild-type mice. Our results revealed that MHC class $\mathrm{II}^{+}$LCs in the corneal epithelium are significantly, but not entirely, suppressed in CCR5 $5^{-/-}$mice compared with wildtype control animals, whereas no significant differences in CCR1-, CCR2/MIP-1 $\alpha$-, and MIP-1 $\alpha$-KO are appreciated compared with controls. The finding that blockade of the CCR5 ligands RANTES and MIP- $1 \beta$ decreased the number of MHC class $\mathrm{II}^{+}$LCs also strongly supports the functional relevance of CCR5 in the recruitment of MHC class $\mathrm{II}^{+}$LCs.

Our data further demonstrate that the resident limbal $\mathrm{CD}_{11 \mathrm{C}^{+}}$LCs were uniformly CCR $5^{-}$. After corneal stimulation with cautery, however, CCR $5^{+}$LCs could be observed infiltrating the corneal periphery, indicating the direct role of CCR5 in the recruitment of corneal LCs, extending the previously shown role of the proinflammatory cytokines IL-1 and TNF- $\alpha$ in this process. These CCR $5^{+}$LCs are mostly immature, whereas most mature LCs in the cornea fail to express this receptor. CCR5 is therefore mediating the initial migration of immature LCs into the epithelium, and is being downregulated once these migrated LCs reach a more mature stage in the cornea. What we cannot determine as yet is whether the CCR ${ }^{+}$LCs are derived from the normally $\mathrm{CCR} 5^{-}$limbal LCs that upregulate CCR5 in response to proinflammatory cytokines and are than chemotactically drawn to the cornea before acquiring a high maturation state and MHC class II expression, or whether they represent a distinct subset of LCs or LC precursors that express CCR5 and are recruited from the limbal intravascular compartment in response to local inflammation in the cornea.

The conclusion that CCR5 function is associated with the mobilization of LCs into the corneal epithelium is based on several lines of investigation. First, promotion of LC recruitment was associated with upregulation of both CCR5 and its associated ligands. Second, the suppression of LC mobilization by cytokine modulation was associated with suppression in gene expression for CCR5-associated ligands; and third, deletion of the CCR5 gene and blockade of its ligands RANTES and MIP-1 $\beta$ led to significant suppression in LC recruitment.

We observed that the expression of CCR5, which is associated with LC migration, is inversely related to the maturational stage of LCs. This observation is indeed well confirmed for a variety of APC populations and chemokine receptors responsible for their migration. ${ }^{31-34}$ For example, it is known that the chemokine receptor CCR6 can initiate recruitment of immature DC subsets to inflamed peripheral sites, ${ }^{31,35-36}$ whereas other chemokine systems (CCR7, ELC/MIP-3 $\beta$ ) can direct the migration of mature Ag-bearing DCs from the periphery to lymphoid organs, where they stimulate $\mathrm{T}$ cells ${ }^{1,32,34,40-42} \mathrm{Al}-$ though we do not have any data at this time that demonstrate definitively similar switching of differential chemokine receptors in corneal APCs, including LCs, it is tempting to speculate that other chemokine systems distinct from CCR5 (and its ligands RANTES and MIP-1 $\beta$ ) mediate the APC emigration from the cornea to lymphoid organs.

It is important to underscore the limitations of this study. First, we were not able to demonstrate complete suppression of the recruitment of MHC class $\mathrm{II}^{+}$LCs in CCR5-KO mice, suggesting that other molecular pathways may also be involved in mediating LC recruitment to the cornea. Other candidates include CCR6 and its ligand MIP-3 $\alpha$, which have been shown to be involved in the recruitment of LCs into the epidermis. ${ }^{36,41}$ In our preliminary study, CCR6 are expressed in the normal mouse corneal epithelium under a confocal microscope and blockade of CCR6 neutralized Ab with subconjunctival injection partially suppressed the recruitment of MHC class $\mathrm{II}^{+}$LCs (Yamagami S, unpublished observation, 2004). Further functional study of the corneal epithelium, using the CCR6-KO mouse and a neutralizing Ab to MIP-3 $\alpha$ should be undertaken Second, given the complex redundancy of the chemokine receptor-ligand systems, we were unable to identify specifically whether both RANTES and MIP- $1 \beta$ or a ligand alone are involved in the recruitment of corneal LCs. Finally, we have recently identified a highly immature/precursor LC population in the corneal epithelium. ${ }^{2,43}$ Although our data do not differentiate between the role of the CCR5 chemokine system in the mobilization of these resident immature LCs (none of the highly immature Ia-negative LCs express CCR5) and the novel recruitment of LCs into the epithelium, we cannot rule out that CCR5, or its associated ligands, may impact these resident cells indirectly. This is highly unlikely, because the role of CCR5, so far, has been limited to the chemotaxis of APCs and not to their maturation or sensitization. ${ }^{37-38}$

Herein we provide data, for the first time that specifically identify the role of CCR5 in initiating the mobilization of LCs to the cornea. Our data suggest that CCR5 and its associated ligands play a critical role in mediating the recruitment and mobilization of MHC class $\mathrm{II}^{+}$LCs into the corneal epithelium. Targeting the CCR5 chemokine system may serve as an appro- 
priate model for the prevention or treatment of corneal inflammation like in microbial keratitis or allograft rejection.

\section{References}

1. Williamson JSP, DiMarco S, Streilein JW. Immunobiology of Langerhans cells on the ocular surface. Invest Ophthalmol Vis Sci. 1987;28:1527-1532.

2. Hamrah P, Zhang Q, Liu Y, Dana MR. Novel characterization of MHC class II-negative population of resident corneal Langerhans cell-type dendritic cells. Invest Ophthalmol Vis Sci. 2002;43:639646.

3. Gillette TE, Chandler JW, Greiner JV. Langerhans cells of the ocular surface. Ophthalmology. 1982;89:700-711.

4. Dekaris I, Zhu S, Dana MR. TNF- $\alpha$ regulates corneal Langerhans cell migration. J Immunol. 1999;162:4235- 4239.

5. Dana MR, Dai R, Zhu S, Yamada J, Streilein JW. Interleukin-1 receptor antagonist suppresses Langerhans cell activity and promotes ocular immune privilege. Invest Ophthalmol Vis Sci. 1998; 39:70-77.

6. Jager MJ, Gregerson DS, Streilein JW. Regulators of immunological responses in the cornea and the anterior chamber of the eye. Eye. 1995;9:241-246.

7. McLeish W, Rubsamen P, Atherton SS, Streilein JW. Immunobiology of Langerhans cells on the ocular surface. II. Role of central corneal Langerhans cells in stromal keratitis following experimental HSV-1 infection in mice. Reg Immunol. 1989;2:236-243.

8. Asbell PA, Kamenar T. The response of Langerhans cells in the cornea to herpetic keratitis. Curr Eye Res. 1987;6:179-182.

9. Miller JK, Laycock KA, Nash MM, Pepose JS. Corneal Langerhans cell dynamic after herpes simplex virus reactivation. Invest $O p h$ thalmol Vis Sci. 1993;34:2282-2290.

10. Hazlett LD, Moon MM, Dawisha S, Berk RS. Age alters ADPase positive dendritic (Langerhans) cell response to $\mathrm{P}$. aeruginosa ocular challenge. Curr Eye Res. 1986;5:343-355.

11. Jager MJ, Bradley D, Atherton S, Streilein JW. Presence of Langerhans cells in the central cornea linked to the development of ocular herpes in mice. Exp Eye Res. 1992;54:835-841.

12. Hazlett LD, McClellan SA, Rudner XL, Barrett RP. The role of Langerhans cells in Pseudomonas aeruginosa infection. Invest Ophthalmol Vis Sci. 2002;43:189-197.

13. Sano Y, Ksander BR, Streilein JW, Minor H, rather than MHC, alloantigens offer the greater barrier to successful orthotopic corneal transplantation in mice. Transpl Immunol. 1996;4:53-56.

14. Sano Y, Ksander BR, Streilein JW. Murine orthotopic corneal transplantation in high-risk eyes: rejection is dictated primarily by weak rather than strong alloantigens. Invest Ophthalmol Vis Sci. 1997; 38:1130-1138.

15. Streilein JW. Immunobiology and immunopathology of corneal transplantation. Chem Immunol. 1999;73:186-206.

16. Dana MR, Yamada J, Streilein JW. Topical interleukin 1 receptor antagonist promotes corneal transplant survival. Transplantation. 1997;63:1501-1507.

17. Niederkorn JY, Peeler JS, Mellon J. Phagocytosis of particulate antigens by corneal epithelial cells stimulate interleukin-1 secretion and migration of Langerhans cells into the central cornea. Reg Immunol. 1989;2:83-90.

18. Niederkorn JY. Effects of cytokine-induced migration of Langerhans cells on corneal allograft survival. Eye. 1995;9:215-218.

19. Cumberbatch M, Dearman RJ, Kimber I. Langerhans cells require signals from both tumour necrosis factor-alpha and interleukin-1 beta for migration. Immunology. 1997;92:388-395.

20. Cumberbatch M, Kimber I. Tumor necrosis factor-alpha is required for accumulation of dendritic cells in draining lymph nodes and for optimal contact sensitization. Immunology. 1995;84:31-35.

21. Wang B, Kondo S, Shivji GM, Fujisawa H, Mak TW, Sauder DN. Tumor necrosis factor receptor II (p75) signaling is required for the migration of Langerhans cells. Immunology. 1996;88:284288.
22. Gerard C, Frossard JL, Bhatia M, et al. Targeted disruption of the beta-chemokine receptor CCR1 protects against pancreatitis-associated lung injury. J Clin Invest. 1997;100:2022-2207.

23. Yamagami S, Miyazaki D, Ono S, Dana MR. Differential chemokine gene expression after corneal transplantation. Invest Ophthalmol Vis Sci. 1999; 40:2892-2897.

24. Yamada J, Dana MR, Zhu SN, Alard P, Streilein JW. Interleukin 1 receptor antagonist suppresses allosensitization in corneal transplantation. Arch Ophthalmol. 1998;116:1351-1357.

25. Qian Y, Dekaris I, Yamagami S, Dana MR. Topical soluble tumor necrosis factor receptor type I suppresses ocular chemokine gene expression and rejection of allogeneic corneal transplants. Arch Ophthalmol. 2000;118:1666-1671.

26. Hamrah P, Liu Y, Zhang Q, Dana MR. The corneal stroma is endowed with significant numbers of resident dendritic cells. Invest Ophthalmol Vis Sci. 2003;44:581-589.

27. Hamrah P, Liu Y, Zhang Q, Dana MR. Alterations in corneal stromal dendritic cell phenotype and distribution in inflammation. Arch Ophthalmol. 2003;121:1132-1140.

28. Luster AD. Chemokines-chemotactic cytokines that mediate inflammation. $N$ Engl J Med. 1998;338:436- 445.

29. Ward SG, Bacon K, Westwick J. Chemokines and T lymphocytes: more than an attraction. Immunity. 1998;9:1-11.

30. Springer TA. Traffic signals for lymphocyte recirculation and leukocyte emigration: the multistep paradigm. Cell. 1994;76:301-314.

31. Yanagihara S, Komura E, Nagafune J, Watarai H, Yamaguchi Y. EBI1/CCR7 is a new member of dendritic cell chemokine receptor that is up-regulated upon maturation. J Immunol. 1998;161:30963102.

32. Dieu-Nosjean MC, Massacrier C, Homey B, et al. Macrophage inflammatory protein 3 alpha is expressed at inflamed epithelial surfaces and is the most potent chemokine known in attracting Langerhans cell precursors. J Exp Med. 2000;192:705-718.

33. Rubbert A, Combadiere C, Ostrowski M, et al. Dendritic cells express multiple chemokine receptors. J Immunol. 1998;160: 3933-3941.

34. Dieu-Nosjean MC, Vicari A, Lebecque S, Caux C. Regulation of dendritic cell trafficking: a process that involves the participation of selective chemokines. J Leukoc Biol. 1999;66:252-262.

35. Sato K, Kawasaki H, Nagayama H, et al. Signaling events following chemokine receptor ligation in human dendritic cells at different developmental stages. Int Immunol. 2001;13:167-179.

36. Charbonnier AS, Kohrgruber N, Kriehuber E, Stingl G, Rot A, Maurer D. Macrophage inflammatory protein 3alpha is involved in the constitutive trafficking of epidermal Langerhans cells. $J$ Exp Med. 1999;190:1755-1768.

37. Sallusto F, Palermo B, Lenig D, et al. Distinct patterns and kinetics of chemokine production regulate dendritic cell function. Eur J Immunol. 1999;29:1617-1625.

38. Combadiere C, Ahuja SK, Tiffany HL, Murphy PM. Cloning and functional expression of CC CKR5, a human monocyte CC chemokine receptor selective for MIP-1 (alpha), MIP-1 (beta), and RANTES. J Leukoc Biol. 1996;60:147-152.

39. Samson M, Labbe O, Mollereau C, Vassart G, Parmentier M. Molecular cloning and functional expression of a new human CCchemokine receptor gene. Biochemistry. 1996;35:3362-3367.

40. Fan L, Reilly CR, Luo Y, Dorf ME, Lo D. Ectopic expression of the chemokine TCA4/SLC is sufficient to trigger lymphoid neogenesis. J Immunol. 2000;164:3955-3959.

41. Carramolino L, Kremer L, Goya I, et al. Down-regulation of the beta-chemokine receptor CCR6 in dendritic cells mediated by TNF-alpha and IL-4. J Leukoc Biol. 1999;66:837-844.

42. Iwasaki A, Kelsall BL. Localization of distinct Peyer's patch dendritic cell subsets and their recruitment by chemokines macrophage inflammatory protein (MIP)-3alpha, MIP-3beta, and secondary lymphoid organ chemokine. J Exp Med. 2000;191:1381-1394.

43. Liu Y, Hamrah P, Zhang Q, Taylor AW, Dana MR. Draining lymph nodes of corneal transplant hosts exhibit evidence for donor major histocompatibility complex (MHC) class II-positive dendritic cells derived from MHC class II-negative grafts. J Exp Med. 2002;195: 259-268. 